\title{
En tiempos de pandemia, el poder se convierte en amenaza para los Derechos
}

\author{
In times of pandemic, power becomes a threat to Human Rights
}

Agustín GARCía FAURE

RICARDO DEL BARCO ${ }^{2}$

$0^{\circ}$ lus Comitiãlis / Año 4, Número 7 / enero - junio 2021 / pp. 62-75 / ISSN: 2594-1356 Recepción: 18 de agosto de 2020 / Aceptación: 17 de noviembre de 2020

\section{(C) $(\mathbb{Q} \otimes(\odot)$}

Esta obra está bajo licencia Creative Commons

Attribution-NonCommercial-ShareAlike $\quad 4.0$

International (CC BY-NC-SA 4.0)

Resumen: Los autores plantean como una situación extraordinaria la pandemia, esta se convierte en una oportunidad para el crecimiento del poder estatal que lleva a una clara vulneración de los derechos humanos. La gran tentación es que, en medio de algo impensado, los gobernantes aprovechen la oportunidad de avanzar hacia un modelo claramente autoritario. Una vez más se impone el principio de la sabiduría clásica, "distinguir para unir", tomar medidas extraordinarias para hacer frente a situaciones extraordinarias, no es lo mismo que forjar poder a expensas de los derechos de la ciudadanía. Lo contrario es sumar a la desgracia pandémica, la peor de las desgracias, el totalitarismo estatal.

Palabras clave: Pandemia; Poder Estatal; Violencia Institucional; Derechos Humanos.

Abstract: The authors propose how an extraordinary situation, the Pandemic, becomes an opportunity for the growth of state power that leads to a clear violation of human rights. The great temptation is that in the midst of something unexpected, the rulers seize the opportunity to move towards a clearly authoritarian model. Once again, the principle of classical wisdom is imposed, "distinguish to unite", taking extraordinary measures to face extraordinary situations, is not the same as forging power at the expense of the rights of citizenship. The opposite is to add to the pandemic misfortune, the worst of misfortunes, state totalitarianism.

Key words: Pandemic; State Power; Institutional Violence; Human rights.

http://orcid.org/0000-0002-0429-411X. / Correo electrónico: agustinsn@hotmail.com

${ }^{1}$ Universidad Nacional de Córdoba. Córdoba, Argentina.

http://orcid.org/0000-0002-1928-1821. / Correo electrónico: estudiodelbarcoserra@gmail.com

${ }^{2}$ Universidad Nacional de Córdoba. Córdoba, Argentina. 


\section{INTRODUCCIÓN}

En el contexto actual que atraviesa la Argentina a partir de la pandemia por coronavirus, resulta de utilidad analizar y determinar el poder del Estado y algunas de sus consecuencias negativas que vulneran los derechos elementales de la ciudadanía. Este artículo plantea algunas consideraciones sobre la relación entre Estado y pandemia, donde entran en juego diversas decisiones que trasforman el escenario estatal en un lugar carente de espacios públicos para el debate de la cosa común, como también, un lugar donde crece la violencia institucional.

Observamos a la sociedad civil como sujeto necesario para reclamar la protección de los derechos elementales, como también vemos la neutralización que produce la pandemia respecto a la participación de la ciudadanía. Hoy la cuarentena obligatoria produce el desinterés de la población para reclamar por sus derechos. Por lo tanto, es necesario reivindicar mecanismos que limiten el poder del Estado, como la voz que alza el pueblo en las movilizaciones y que tiene como objetivo la reflexión del soberano para tomar decisiones que procuren el bien del pueblo. De esta manera, en los capítulos siguientes se realiza un análisis de la situación presente por la pandemia. Desde la revisión y análisis documental, con un estudio detallado de casos fatales ocurridos durante la cuarentena que se vive en Argentina.

\section{EL PODER DEL ESTADO Y LA PANDEMIA}

La pandemia que nos agobia, casi desde el comienzo de este año, es un imprevisto sin precedentes y sin culpables. Si seguimos el lenguaje de los antiguos juristas, no se trata de un hecho del príncipe, sino de un caso fortuito. Pero ya en medio de este nuevo desafío, los hechos del príncipe, además de la voluntad de los ciudadanos, comienzan a tener sentido. Siempre el príncipe, tiene la gran tentación de ejercer su poder, sin cortapisas y buscando ampliarlo lo más posible. Diríamos que está en la naturaleza de las cosas. El poder tiende a expandirse hasta donde encuentra límites. Mientras más extraordinaria es la situación, más se exacerba la tentación apuntada. Por otra parte, en dichas situaciones la ciudadanía tiende a sentir temor y pasa a quedar como anestesiada. Podríamos describir la evolución de la actitud del poder, frente a esta situación de pandemia. El príncipe se presenta desempeñando un rol de paternalismo seductor. Como el paterfamilias el cual acoge bajo su protección a los hijos y clientes, asegurándoles resguardo y sosiego, les pide que obedezcan sus instrucciones y les señala que hay un afuera hostil que busca destruirlos.

La cuarentena es el mandato del poder y es aceptado con benevolencia por los ciudadanos, que no se proponen discutir en el ágora lo que es más conveniente para 
los destinos de los ciudadanos, sino que la asumen como súbditos obedientes. Desde el fondo de la historia aparece la figura del dictador en la república romana. Cuando la república estaba en peligro se confería la totalidad del poder al dictador. Pero claro esta que esta traslación del poder total a manos de una persona tenía un plazo limitado. Cesado el mismo, volvían a funcionar las instituciones de la República. El recuerdo histórico nos permite entender la situación presente. Lo que comenzaba como una medida excepcional para asumir un riesgo inesperado, tiende en muchos países, más de los que uno podría desear, a convertirse en un estilo de gestión de la crisis. El padre seductor, aunque autoritario, tiende a mutar en el autócrata permanente que edifica un sistema de control total. Todo atisbo de otra mirada acerca del manejo de la crisis es visto desde el poder, como una insolencia peligrosa que amenaza la vida de todos. El príncipe cada vez concentra más poder y con ello se acrecienta el temor.

La afirmación de Montesquieu, acerca del despotismo, cuando afirmaba que el déspota debe mantener siempre el brazo en alto, para infundir temor, pues de lo contrario desaparece el despotismo, cobra en las situaciones presentes una extraordinaria vigencia. Sin temor no hay despotismo. Una exegesis de estos largos meses de Pandemia y cuarentena, nos muestra los siguientes síntomas:

1. Crecimiento del Poder del Ejecutivo, anomia del Poder Legislativo, Poder Judicial en respetuoso silencio.

2. Los medios de comunicación nos introducen diariamente en un escenario de infestados y muertos. Cifras abrumadoras y establecimiento de un ranking de desgracias que tiende a mostrar que el país del que salen las estadísticas está menos peor que los otros.

3. Los cuidados necesarios se convierten en fuente desconfianza ciudadana, de manera tal que el otro es un enemigo potencial.

4. El lenguaje pierde su significación originaria y tiende a ser sustituido por un argot, hijo de supuestos especialistas, que la virtualidad es saludable por sí misma, que el distanciamiento social, nombre nuevo del distanciamiento interpersonal es una virtud. Que el encierro de las personas, que han cometido en delito de ser mayores, es una medida benefactora. Todo ello, aunque la experiencia indica que los mayores índices de mortalidad ocurren allí.

5. Se nos enseña que la impiedad de morir solos es un acto de responsabilidad social, y que honrar a los muertos es propagar la epidemia.

6. Frases como "nueva normalidad”, que son contradictorias de por sí, ya que "novedad" y "normalidad", son antagónicas; "aplanar la curva”, "esperar el pico", etc., son solo ejemplos de un lenguaje supuesto hijo de infecto logos gobernantes, que solo tienden a aumentar la confusión y generalmente el pánico. Vaya otro ejemplo, la frase publicitaria "quédate en casa”, inicialmente presentada como un amable ruego al resguardo que ampara de peligros, con el paso del tiempo se percibe y se implementa como una verdadera reclusión domiciliaria.

Toda esta situación coloca a las fuerzas de seguridad del Estado en un papel protagonista frente al escenario público, sin un libreto claro y sin ningún tipo de experiencia previa para que su actuación sea diligente frente a la pandemia. 


\section{LA RESPUESTA DEL PODER FRENTE A LA PANDEMIA}

En la Argentina, a raíz de la pandemia de coronavirus, el Poder Ejecutivo Nacional a través del decreto de necesidad urgencia $N^{\circ}$ 297/2020, implementó una cuarentena obligatoria a lo largo y ancho del país. Se estableció que todas las personas debían permanecer en sus residencias habituales o en las residencias en que se encontraran. Se prohibió la circulación por rutas, se remarcó que las personas debían abstenerse de concurrir a sus lugares de trabajo y se autorizó de manera excepcional el desplazamiento para abastecerse de alimentos, medicamentos y artículos necesarios para la higiene personal y del hogar. El plazo temporal de la mediada, en un principio, se extendería desde las 00:00 horas del día 20 de marzo de 2020 hasta el 31 de marzo inclusive. Hoy la Argentina, al 31 de julio de 2020, después de haberse prorrogado de manera continua la decisión de aislamiento, sigue en cuarentena.

El fundamento de esa decisión se vinculaba directamente con la obligación del Estado de proteger la salud pública. Es decir, con el aislamiento se busca neutralizar la propagación del virus, para que la curva de contagios no tenga un ascenso brusco que conlleve a la saturación del servicio de salud público y privado. La esperanza de disminuir los contagios fue y será la meta principal del gobierno de Alberto Fernández 3 . Al respecto, en la conferencia de prensa del 30 de julio del 2020, a cuatro meses del inicio de la cuarentena, el presidente de los argentinos nos decía:

Veo con mucha preocupación la situación [...] Me parece que tenemos que ponernos un poco firmes porque no está funcionando esto [...] Lo que no podemos hacer es dejar que el problema avance[..] Es muy posible que la curva vuelva a subir y tiene que ver con la gente en las calles, con la gente encontrándose, con la gente comiendo un asado (Página 12, 2020).

En cada rincón de la Argentina se vive una verdadera incertidumbre por el avance desenfrenado del Covid-19. Cada día que finaliza se suman más contagios a una lista que parece no tener horizontes. Según el reporte diario del Ministerio de Salud, de fecha 30 de julio de 2020, se confirmaron 6.377 nuevos casos de COVID-19. Con estos registros, suman 185.373 casos positivos en el país.

\section{RECOLECCIÓN DE CASOS DE FUENTE PERIODÍSTICA QUE MUESTRAN LA VIOLENCIA DEL ESTADO A TRAVÉS DE LAS FUERZAS DE SEGURIDAD}

La Coordinadora contra la Represión Policial e Institucional (Correpi) de Argentina, señaló que durante los 90 días iniciales de la cuarentena se registraron aproximadamente 50 informes que describen diferentes hechos de abuso policial en tiempos de pandemia. Textualmente, esta organización que lucha por los derechos humanos y contra la represión del Estado, nos expresaba en su página oficial lo siguiente:

${ }^{3}$ Presidente de la Argentina, electo en la elección presidencial del año 2019. 
En estos 90 días hemos publicado casi 50 reportes con denuncias sobre todo tipo de violencia policial y de otras fuerzas a lo largo y ancho del país: golpizas, torturas, asesinatos, violaciones y desaparición forzada, hechos en los que han participado policías federales, provinciales, municipales, gendarmería, prefectura y servicios penitenciarios (...) El incremento exponencial de detenciones arbitrarias, que se traduce en un aumento de las denuncias por imposición de tormentos en comisarías, también se refleja en una mayor cantidad de personas muertas en dependencias policiales. Entre el 20 de marzo y el 31 de mayo, registramos 23 casos de muertes en lugares de detención, de los cuales 8 corresponden a comisarías y 15 a cárceles, siempre destacando que no son todos los hechos ocurridos, sino los que hasta el momento pudimos confirmar (Coordinadora, 2020).

En pandemia los hechos de violencia donde participan integrantes de las fuerzas de seguridad no han disminuido. A continuación, señalaremos algunos casos ocurridos en diferentes provincias de la Argentina:

1. En la Pampa, un hombre que salió a comprar pan "fue baleado por un agente policial con balas de goma que impactaron en su rostro".

También, en esa provincia, en la ciudad de General Hacha, un hombre que buscaba a su perro fue detenido y golpeado en una comisaria hasta dejarlo con un grave traumatismo de cráneo, su privación de la libertad duró cinco días. Además, en esa provincia se reportó que los detenidos en un complejo carcelario fueron torturados con picana eléctrica.

2. En el Chaco, representantes de las Naciones Unidas denunciaron casos de discriminación y maltratos contra una familia integrante de la comunidad indígena Qom. Las fuerzas policiales de la ciudad de Fontana actuaron de manera violenta y sin límites. El brutal ataque quedó registrado en un video. Además, cuatro jóvenes de la comunidad denunciaron haber sido torturados y abusados en la comisaria. A continuación, trascribimos el testimonio textual de la información:

"Estamos consternados por la violencia con que se realizó este operativo. La función policial debe en todo momento observar los principios de legalidad, necesidad y proporcionalidad, así como la prohibición internacional de tratos crueles o degradantes", comentaron Roberto Valent, coordinador residente de ONU Argentina y Jan Jarab, representante de ONU Derechos Humanos en América del Sur, quienes expresaron solidaridad con las personas afectadas. "El apego a las normas internacionales que rigen la actuación policial es aún más fundamental debido al papel de las policías al implementar las medidas extraordinarias frente a COVID-19. Cualquier respuesta a la pandemia debe ser proporcional y no discriminatoria" (ONU, 2020).

3. En Tucumán, las fuerzas policiales secuestraron y asesinaron a Luis Ezpinosa. "La delegación Tucumán de la Secretaría de Derechos Humanos de la Nación denunció en sede penal y pidió que se investiguen presuntos delitos cometidos por personal policial en el marco de la vigilancia por el Aislamiento Social Obligatorio".

4. En San Luis, otra lamentable noticia, se sumó la aparición sin vida de Flo- 
rencia Magalí Morales y Franco Maranguello, un niño de tan solo 16 años. Ambos, fueron encontrados en los calabozos que los albergaban por haber salido de sus casas en cuarentena.

5. En Buenos Aires, exactamente en la localidad de Pedro Luro, la desaparición de Facundo Astudillo Castro. Un joven de 22 años de edad que fue visto por últimas veces el día 30 de abril de 2020, cuando salió de Pedro Luro hacia Bahía Blanca, destino al cual nunca llegó. Hay testigos que afirman haber visto al joven cuando policías lo subían a un patrullero.

6. En Buenos Aires, en el Partido de La Matanza, un patrullero de la gendarmería es filmado cuando circulaba reproduciendo un audio de la película "La Purga", mensaje que aterrorizaba a la población en medio de la cuarentena por el coronavirus. Ese hecho demuestra la irresponsabilidad o la inmadurez de los ocupantes de ese patrullero.

7. En Córdoba, otro terrible hecho, el asesinato de Valentino Blas Correa un joven de 17 años que recibió un disparo por la espalda, como respuesta por eludir -con dos amigos- un control policial, cuando se dirigían de regreso a sus respectivas viviendas. En relación con el caso, los medios de comunicación señalaron que el funcionario a cargo de la investigación;

"informó que los policías habrían efectuado "cuatro o cinco disparos" al automóvil durante la persecución, y que "uno dio en la espalda" del adolescente que murió. Además, afirmó que "no hubo ningún tipo de intercambio de disparos", ya que en las cercanías del automóvil de los chicos encontraron un revólver que, supuestamente, "plantaron" los policías. Prunotto también detalló que los dos efectivos detenidos fueron imputados del delito de "homicidio calificado agravado por el uso de arma de fuego" (Télam, 2020).

8. En Río Negro, una mujer salió a pasear su perro para que realice sus necesidades y terminó demorada en una comisaria de la ciudad de San Carlos de Bariloche. La mujer -al momento de la detención- comenzó a gritar: "Auxilio" "Ayuda por favor". La ciudadanía a través de los medios digitales reclamaba su liberación.

\begin{tabular}{|c|c|c|}
\hline $\begin{array}{l}\text { 1-MARUEL C6́MEZ (23) } \\
\text { PBA (POUCLA OE LA CLDAO OE BS AS.) }\end{array}$ & $\begin{array}{l}\text { 11-JosE ÁVILA (35) } \\
\text { PROUNCLA OE É́ROOBA (POUCLA OE COROOBA) }\end{array}$ & $\begin{array}{l}\text { 22-MAXIMILIANO MUNOZZ (30) } \\
\text { PBA (POLCCA BONAEREISE) }\end{array}$ \\
\hline $\begin{array}{l}\text { 2-CÉSAR OBES (17) } \\
\text { PBA (POUCIÁ FEOERAL) }\end{array}$ & $\begin{array}{l}\text { 12-BRANDON ROMERO (18) } \\
\text { PBA (POUCL BOMGREVISE) }\end{array}$ & $\begin{array}{l}\text { 23-JORGE PADILLA (40) } \\
\text { PBA (POUCA BOMURERISE) }\end{array}$ \\
\hline 3-ALAN MAIDANA (19) & 13- SIN IDENTIFICAR (15) & 24-SANTLAGO SANTUCHO (17) \\
\hline 4-LUCAS BARRIOS (18) & 14-LUCAS VERÓN (18) & 25-JUAN IGNACIO RAMOS (27) \\
\hline PBA (POLCIA FEDERAL) & PBA (POLCCA BOMAERENSE) & PQA (POUCL BOMGEREISE) \\
\hline $\begin{array}{l}\text { 5-ALEXIS LUCERO (17) } \\
\text { PBA (POUCCA FEDERAL) }\end{array}$ & $\begin{array}{l}\text { 15-SERGIO (20) } \\
\text { PBA (POUCCA BONAEREISE) }\end{array}$ & 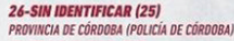 \\
\hline 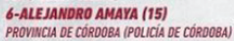 & $\begin{array}{l}\text { 16-DAAIEL MONTES (19) } \\
\text { PBA (POUCL BOOMEREIISE) }\end{array}$ & $\begin{array}{l}\text { 27-FRANCO SOSA (23) } \\
\text { PROVICLA OE CORDOBA (POUCA OE COROOOBA) }\end{array}$ \\
\hline 7-AUGUSTO ITURRALDE (25) & 17-EZEOUIEL GAUTO (22) & 28-SIN IDENTIFICAR (22) \\
\hline PBA PPOUCLA FEOERAL & PBA (POLCL FEOERAL) & PBA (POUCL BOMUEREINE) \\
\hline $\begin{array}{l}\text { 8-DIEGO ARZAMENDIA (23) } \\
\text { PBA (POUCCA FEDERAU) }\end{array}$ & $\begin{array}{l}\text { 18-ROQUE GALLO (27) } \\
\text { CABA IGENORRMERIA MaCLOOAUU }\end{array}$ & 29-SIN IDENTIFICAR (25) \\
\hline 9-FACUNDO SCALZO (20) & 19-RUBÉN SARSO (3O) & 30-DAMIEL DUARTE (40) \\
\hline \multirow{3}{*}{$\begin{array}{l}\text { 10-FERNANDO LEGUIZAMÓN (31) } \\
\text { PBA (POUCCI BOMARRESEE) }\end{array}$} & $\begin{array}{l}\text { CABA (POUCIA DE LA CGOAOA) } \\
\text { 20-MAXIMIUANO GOMEZ (23) }\end{array}$ & 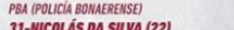 \\
\hline & 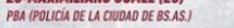 & PBA (POLCLA OE $\triangle A$ CUDAO OE BS.AS) \\
\hline & $\begin{array}{l}\text { 21- GONZALO BORDA (24) } \\
\text { PBA (POLCIA BOMAERENSE) }\end{array}$ & 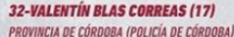 \\
\hline
\end{tabular}

Fig. 1. La imagen da cuenta de la cantidad de casos registrados por la utilización abusiva del arma de fuego por parte de las fuerzas de seguridad en Argentina y bajo cuarentena. Estos hechos se conocen con la expresión "Gatillo fácil" (Observatorio, 2020). 
El apartado anterior nos muestra un proceso exacerbado por la pandemia, un ejemplo de lo que se denomina violencia institucional. Esta constituye un claro signo de transgresión de los principios fundamentales del Estado de Derecho. Como sabemos, este supone el ejercicio del legítimo poder de coacción del Estado, sujeto a la ley y con pleno respeto a los derechos humanos.

\section{LA VIOLENCIA INSTITUCIONAL}

$\mathrm{Al}$ analizar sobre qué entendíamos sobre violencia institucional pudimos consensuar en la aproximación de la siguiente noción:

La violencia institucional es la acción desmedida e irracional que el poder Estatal descarga contra el ciudadano, y que despoja a este último de la dignidad humana, con un resultado negativo e irreparable de los derechos humanos, como la libertad, la integridad física y la vida de las personas. Nos encontramos ante un uso indebido del poder del Estado que violenta a todo nuestro sistema democrático.

Con la lectura de un trabajo titulado; Los derechos humanos frente a la violencia institucional, elaborado por la República Argentina a través del Ministerio de Justicia de la Nación, la Secretaria de Derecho Humanos y el Ministerio de Educación, pudimos advertir que la violencia institucional hace;

[...] referencia a un amplio conjunto de situaciones que, ejercidas desde instituciones públicas por medio de sus funcionarios/as, tienen como consecuencia la vulneración y violación de derechos de las personas. Si quisiéramos precisar las formas más graves que adoptan estas prácticas en la actualidad haríamos referencia a graves violaciones a los derechos humanos, abusos e ilegalidades que van desde detenciones arbitrarias y torturas hasta asesinatos por "gatillo fácil". También vimos que estas prácticas se desarrollan de forma sistemática y estructural (como acciones y omisiones) y tienen como resultado retardar, obstaculizar o impedir el acceso y garantía a los derechos humanos.(Presidencia, 2013).

La ciudadanía argentina, al igual que los extranjeros y extranjeras residentes en el país, han sufrido y continúan sufriendo hechos aberrantes de violencia institucional por parte de algunos integrantes de las fuerzas de seguridad. En la historia de nuestro país encontramos numerosos casos de violencia institucional. Entre tantos, podemos mencionar el ocurrido el 8 de mayo de 1987, donde tres jóvenes que se encontraban sentados en el barrio de Ingeniero Budge, fueron asesinados por agentes de la Policía Bonaerense. Un oscuro acontecimiento de gatillo fácil que se recuerda como la masacre de Bugne, y que movilizó al Estado -allá por el año 2013- para declarar al 8 de mayo como el Día Nacional de la Lucha contra la Violencia Institucional, con el objetivo de concientizar las graves vulneraciones a los derechos humanos perpetrados por las fuerzas de seguridad. 
La violencia institucional y en particular la ejecutada por las fuerzas de seguridad están presentes en todas las democracias latinoamericanas. Esta afirmación forma parte de una realidad que se encuentra en la agenda pública de todos los Estados. Las víctimas, sus familiares y los distintos grupos de la sociedad luchan constantemente para ubicar esta problemática en la mesa de prioridades de los representantes del pueblo. Esta realidad de abusos policiales en Latinoamérica ha quedo reflejada en los diversos textos correspondientes a las sentencias de la Corte IDH que tratan hechos vinculados con las fuerzas de seguridad de los Estados. Con respecto a la Argentina, y en relación con hechos de violencia institucional o abuso policial, podemos mencionar los siguientes casos:

- Bulacio: Causa donde podemos hallar, precisamente en la prueba documental, el dictamen pericial de Emilio García Méndez que exponía:

Los abusos policiales mantienen una intensidad y frecuencia preocupante en América Latina. Es razonable plantear la hipótesis de que existe una fuerte relación de causa efecto entre la frecuencia e intensidad de los abusos policiales y las detenciones arbitrarias, y de estas últimas, a su vez, y con el concepto de "protección", tal como éste se presenta en la cultura jurídica "minorista. (Corte IDH, 2003).

- Torres Millacura y otros: Causa donde también se dejó en claro la existencia de abusos policiales:

60. El Estado reconoció que en la Provincia del Chubut se cometían abusos policiales en perjuicio de jóvenes de escasos recursos, en el marco de los cuales tuvieron lugar las detenciones del señor Torres Millacura en septiembre de 2003 por parte de la policía, así como su detención y posterior desaparición forzada desde el 3 de octubre de 2003 en la ciudad de Comodoro Rivadavia, localizada en dicha Provincia. El Tribunal observa que en el peritaje rendido por la señora Sofía Tiscornia durante la audiencia pública (supra párr. 40), ésta se refirió extensivamente al "hostigamiento permanente" perpetrado por la policía provincial en la Provincia del Chubut con el amparo de normas contravencionales o para la averiguación de antecedentes o de identidad. La perita sostuvo que "las normas que habilitan a la policía a detener reiteradamente [a las] personas pueden concluir [...] en varias ocasiones en muertes, torturas y, en este caso, en una desaparición", impactando a "los sectores más desprotegidos de la sociedad [...] (Corte IDH, 2011).

En decir, los abusos policiales son una amenaza con una larga historia en la Argentina y en Latinoamérica, y que hoy mantienen plena vigencia, con un crecimiento exponencial en nuestro país a partir de la pandemia ocasionada por coronavirus (COVID-19). Hay que destacar, que nuestro país reconoce la prexistencia de estas conductas contrarias a los derechos humanos, sin embargo, no ha podido encontrar el método para su erradicación. En este sentido, observemos el reciente reconocimiento de responsabilidad internacional que la Argentina ha realizado ante la Corte IDH, en relación con los hechos de violencia institucional que dan cuenta los casos; José Delfín Acosta y familiares vs. Argentina y Fernández Prieto y Tumbeiro vs. Argentina. 
En la plena vigencia del Estado de Derecho, no solo es necesario el funcionamiento pleno de los poderes del Estado, el Legislativo, como freno del Ejecutivo y el Judicial como garante los derechos fundamentales, sino de la necesidad de una sociedad civil interesada en el bienestar general.

\section{LA SOCIEDAD CIVIL}

En este apartado desarrollaremos la actuación de la sociedad civil frente a los graves acontecimientos de violencia institucional que fuimos mostrando en los párrafos anteriores. Entendemos que la sociedad civil es de suma importancia en un Estado democrático, ya que interviene en representación de los intereses de la diversidad, una cualidad que no debe perderse en momentos de crisis como la que hoy atravesamos por la pandemia.

Ahora bien; ¿Qué sucede cuando los ciudadanos no tienen interés en los asuntos públicos y políticos? ¿Qué desafíos enfrenta la sociedad civil ante la escasa participación de los ciudadanos en pandemia? A continuación, buscaremos dar respuesta a las interrogaciones precedentes. Sabemos que la sociedad civil es aquello independiente del Estado, que posee autonomía para generar acciones e interactuar con ellas ante el Estado, siempre dentro del respecto de la normativa vigente. Existe entre la sociedad civil y Estado una relación de intercambio e interdependencia, puesto que la sociedad civil acciona libremente gracias a las concesiones o lineamientos legales que el Estado ha impartido a sus efectos, y este último, gestiona la cosa pública gracias a la legitimación que obtiene de la obediencia de la sociedad civil al cuerpo normativo preexistente. La sociedad civil es la amalgama de diversos grupos que se proyectan para tomar acción en representación de los intereses generales de la comunidad. Una de las notas características de la sociedad civil es el pluralismo de sus integrantes, los diversos sectores que la integran. Cada uno de ellos, aportando intereses que la sociedad civil representará con equidad y sin distinciones. Como ha señalado Marta Ochman (2004) la sociedad civil debe entenderse "como la capacidad de acción colectiva” (p. 475).

Todo individuo tiene el derecho a participar en los procesos de decisión de las cuestiones públicas. Observando los mecanismos legales que facilitan su participación. Consideramos que cuando hay poca participación de los ciudadanos, o de grupos o sectores minoritarios, existe el riesgo de que la sociedad civil sea manipulada por un solo sector que promueva sus propios intereses en desmedro de los intereses del resto de los ciudadanos. Es muy importante, y aún en momentos de pandemia, que la ciudadanía se interese por los asuntos públicos y políticos, porque a mayor participación ciudadana menor será la posibilidad para que sectores minoritarios reclamen sólo sus demandas, o bien, se levante sin límites la voz del príncipe. En este sentido, podemos señalar que si la participación es minoritaria no hay plena democracia, lo cual hoy está sucediendo. 
Este razonamiento ha sido convalidado por Julio Alguacil (2008) al mencionar que "no hay plena democracia urbana, si algún colectivo o grupo de sujetos identificado por atributos comunes adscritos (etnia, religión, origen nacional, edad, género etc.) queda excluido del estatus de ciudadanía” (p. 204). Cabe aclarar que para este autor el estatus de ciudadano está determinado por la participación que se tiene en la esfera pública.

Ahora bien, podemos deducir siguiendo a Julio Alguacil (2008) que las causas de desinterés por los asuntos públicos y políticos están dadas por los efectos que produjo; la ciudad industrial primero y la ciudad posindustrial después. Ambas han terminado con la convivencia social y con el espacio público, este último, un elemento indispensable para la participación de los ciudadanos. Causas a las que hoy podemos sumar la gravedad institucional que atraviesa el país por la pandemia, que neutraliza la motivación para participar de los asuntos públicos.

Creemos que la sociedad civil deberá dialogar con el Estado para recuperar ese espacio público capaz de hacer participar a sus ciudadanos en temas del Estado, en especial, respecto a la violencia institucional que vulnera a la ciudadanía sus derechos elementales.

Como nos menciona Julio Alguacil (2008) el "espacio público es, en definitiva, un ámbito privilegiado que ofrece oportunidades inestimables para estimular la participación ciudadana, lo que ayuda a prevenir y oponerse a las dinámicas excluyentes de la desmesurada mercantilización de las metrópolis posindustriales” (pp. 219-220).

Estamos en un momento sin precedentes, donde necesitamos que la sociedad civil de alguna manera motive a la ciudadanía para que despierte su deseo de participar, para reclamar al Estado que garantice y proteja más que nunca los derechos humanos. El desapego de los temas del Estado por parte de un gran número ciudadanos obliga a la sociedad civil a tomar medidas tendientes a enrolar a la mayor cantidad de ciudadanos posibles para que participen de los temas públicos. Una de las hazañas que deberá realizar la sociedad civil es conseguir nuevos e innovadores espacios públicos, sitios donde los ciudadanos dialoguen en busca de soluciones para el bienestar general. Donde se reúnan para elaborar planes de acción para garantizar los derechos humanos. Su desafío es seguir con las transformaciones necesarias para lograr una sociedad que afiance la diversidad y el pluralismo.

Con respecto a los graves acontecimientos de abusos policiales, la sociedad civil se ha movilizado para clamar su voz en busca de la unión nacional, como única fuerza capaz de poner límites al actuar violento del Estado a través de las fuerzas de la seguridad. 


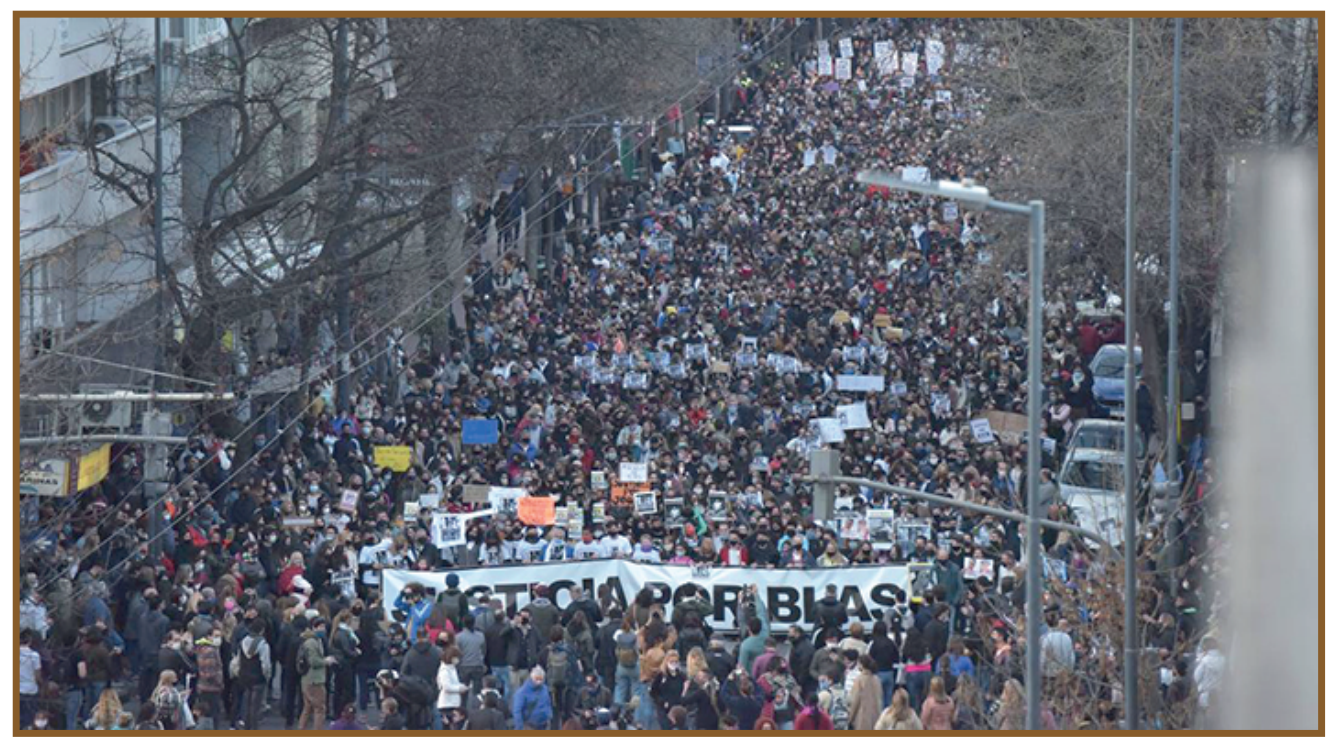

Fig. 2. La imagen corresponde a la marcha realizada en memoria del joven Valentín Blas Correas, quien perdió la vida en manos de la violencia policial (Luque, 2020).

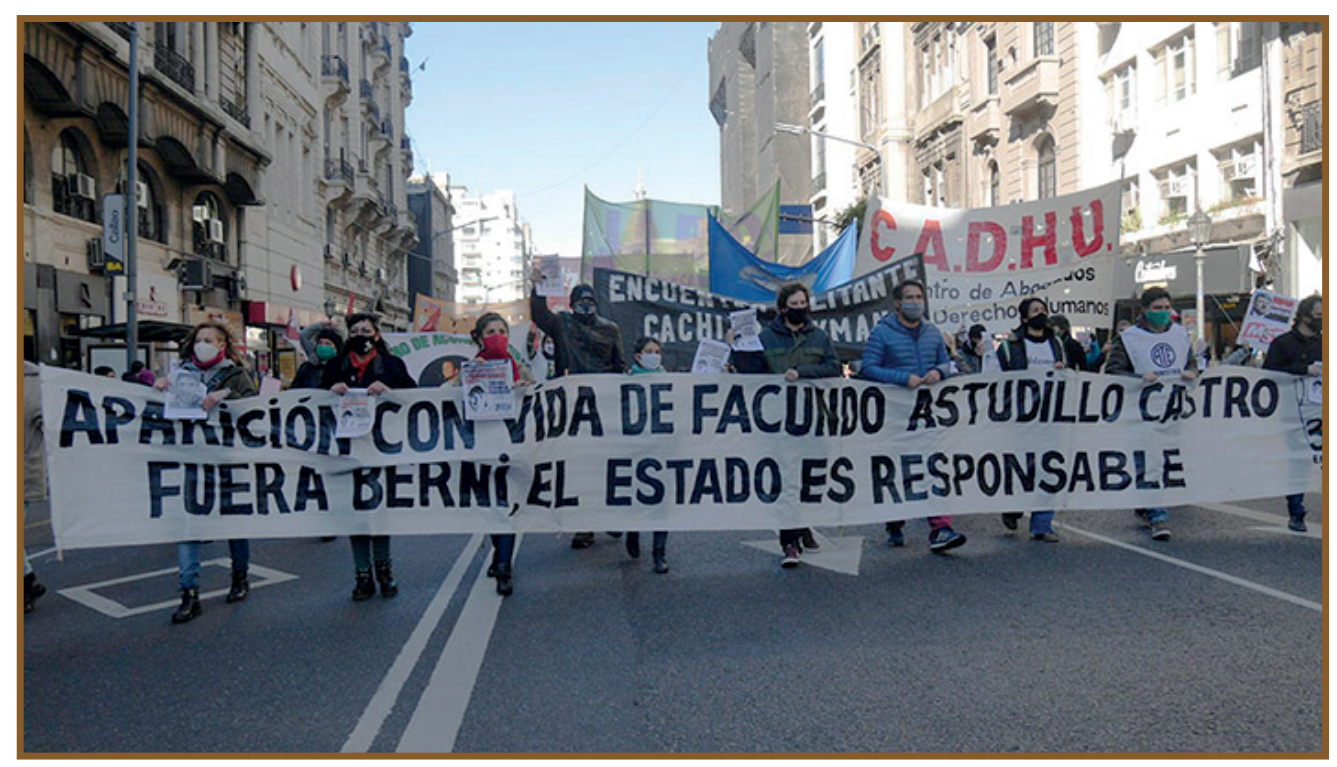

Fig. 3. La imagen corresponde a la marcha realizada por la desaparición de Facundo Astudillo Castro. La ciudanía reclamaba la aparición con vida del joven (Torellas, 2020). 


\section{REFLEXIONES FINALES}

De acuerdo al recorrido expuesto en los párrafos anteriores, es evidente que, en situaciones extraordinarias, se plantean necesidades de respuestas extraordinarias. Pero también es cierto que la emergencia sanitaria que plantea la pandemia no autoriza a realizar cualquier cosa, ni, de cualquier manera, ni de cualquier modo. Frente a estas situaciones formulamos algunas consideraciones finales:

1. El poder estatal, cuya tendencia natural es a crecer, en tiempos de Pandemia, tiene un notable aumento.

2. Ese crecimiento no es percibido inicialmente por la ciudadanía, porque el temor que inspira la Pandemia hace que la búsqueda de refugio y protección sea lo esencial.

3. En esta lógica de temor ciudadano frente a la amenaza desconocida, el poder fiel a su lógica interna crece sin descanso.

4. Ese crecimiento del poder estatal, produce inicialmente un efecto placentero, es casi como una droga que permite a su consumidor inicial alcanzar una situación de tranquilidad placentera.

5. Así como en la droga dependencia se produce un vínculo entre proveedor y consumidor que se va tornando cada vez más degradante entre el poder de los gobernantes y las necesidades ciudadanas. Cada vez más el ciudadano deja de ser aquel que debate, propone, reclama en la plaza pública, para ser el servidor obediente y temeroso.

6. Por último, vale recordar que siempre y aún más en las situaciones de crisis, como las presentes, debe el Poder estatal al servicio de la Justicia. Y es imprescindible recordar aquella magnifica sentencia de Agustín de Hipona, cuando en el siglo V, señalaba que” cuando los gobernantes se apartan de la Justicia, convierten al estado en bandidaje a gran escala".

\section{REFERENCIAS}

1. Alguacil, J. (23 de mayo de 2008). Espacio público y espacio político. La ciudad como el lugar para las estrategias de participación. Polis, Revista de la Universidad Bolivariana (20).

2. Andrade, C. (16 de agosto de 2020). Polémico arresto. Coronavirus en Bariloche: una mujer salió a pasear al perro y la detuvieron entre 5 policías. Clarín. Recuperada de https://www.clarin.com/sociedad/coronavirus-bariloche-salio-pasear-perro-detuvieron -5-policias-presa-dias_0_OdYZtWu2d.html

3. Botana, N. (2006). Poder y Hegemonía. Buenos Aires, Argentina: Emece. Hobbes, T. (2007). Leviatán. Grandes Obras del Pensamiento. Buenos Aires, Argentina: Losada. 
4. Búsqueda de Facundo Astudillo Castro. (31 de julio de 2020). Télam. Recuperado de https://www.telam.com.ar/notas/202007/496842-bahia-blanca-investigadoresbusqueda-desaparicion-facundo-astudillo-castro.html

5. Coordinadora contra la represión policial e institucional. (20 de junio de 2020). Informe de la situación represiva a 90 días de cuarentena. Recuperado de http://www.correpi.org/2020/informe-de-la-situacion-represiva-a-90-dias-de-cuarentena/

6. Coronavirus COVID-19 conocé información y recomendaciones del Ministerio de Salud. (30 de julio de 2020). Argentina.gob.ar. Recuperado de https://www.argentina. gob.ar/coronavirus/informes-diarios/reportes/julio2020

7. Corte Interamericana de Derechos Humanos. Caso Bulacio vs. Argentina. Sentencia de 18 de septiembre de 2003. [Consultado el 31 de julio de 2020]. Recuperado de https://www.corteidh.or.cr/docs/casos/articulos/seriec_100_esp.pdf

8. Corte Interamericana de Derechos Humanos. Caso Torres Millacura y otros vs. Argentina. Sentencia de 26 de agosto de 2011. [Consultado el 31 de julio de 2020]. Recuperado de https://www.corteidh.or.cr/docs/casos/articulos/seriec_229_esp.pdf

9. Decreto 297/2020. Boletín Oficial de la República Argentina, Buenos Aires, 13 de marzo 2020.

10. El Presidente no descartó que haya nuevas restricciones. Alberto Fernández sobre la cuarentena: "Me parece que tenemos que ponernos un poco firmes". (30 de julio de 2020). Página 12. Recuperado de https://www.pagina12.com.ar/281823-alberto-fernandez-sobre-la-cuarentena-me-parece-que-tenemos-

11. Fotografía de Luque, Facundo. (13 de agosto de 2020). La multitudinaria marcha por Blas Correas en Córdoba terminó con un emotivo aplauso. La Voz. Recuperado de https://www.lavoz.com.ar/sucesos/multitudinaria-marcha-por-blas-correas-en-cordoba -termino-con-un-emotivo-aplauso

12. Fotografía de Torellas, María. (30 de julio de 2020). Argentina. Una manifestación exigió en Buenos Aires la aparición con vida de Facundo Astudillo Castro (fotos y video). Resumen Latinoamericano. Recuperado de https://www.resumenlatinoamericano.org/2020/07/30/argentina-una-marcha-multitudinaria-exigio-en-buenos-aires-laaparicion-con-vida-de-facundo-astudillo-castro-fotos-y-video/

13. Histórico reconocimiento ante la Corte Interamericana de Derechos Humanos por casos de Violencia Institucional. (10 de marzo de 2020). Argentina. gov. ar. Recuperado de https://www.argentina.gob.ar/noticias/historico-reconocimiento-ante-la-corteinteramericana-de-derechos-humanos-por-casos-de 
14. La historia de la mendocina detenida, en teoría, por violar la cuarentena y hallada muerta en un calabozo. (14 de mayo de 2020). Explícito, periodismo sin mariposas. Recuperado de https://explicitoonline.com/la-historia-de-la-mendocina-detenida-en-teoria -por-violar-la-cuarentena-y-hallada-muerta-pocas-horas-despues-en-un-calabozo/

15. Morir a los 16 en una celda por violar la cuarentena. (12 de junio de 2020). Diario Norte. Recuperado de https://www.diarionorte.com/192971-morir-a-los-16-en-una-celda-por-violar-la-cuarentena

16. Observatorio Social Antirrepresivo de LID. (7 de agosto de 2020). Informe: las fuerzas represivas del Estado mataron a una persona cada dos días en cuarentena. [Imagen]. Recuperado de http://laizquierdadiario.com/Informe-las-fuerzas-represivas-del-Estado-mataron-a-una-persona-cada-dos-dias-en-cuarentena

17. Ochman, M. (19 de agosto de 2004). Sociedad civil y participación ciudadana. Revista Venezolana de Gerencia (27), pp. 473-489.

18. ONU, Naciones Unidas Derechos Humanos. (3 de junio de 2020). Argentina: ONU advierte discriminación y violencia policial en el Chaco. Recuperado de https:// acnudh.org/argentina-onu-advierte-discriminacion-y-violencia-policial-en-el- chaco/

19. Ordoñez, J. (01 de enero de 2016). Democracia y participación del ciudadano: Un sustento urgente del estado constitucional y de la seguridad Pública en México. Revista de Antropología Experimental (16), pp. 9-25.

20. Pérez Campos, M. (2009). Los Derechos Humanos en la definición de la política democrática. Caracas, Venezuela: Universidad Metropolitana.

21. Policías persiguen a adolescentes que se hallaban en un auto y matan a uno de un tiro en la espalda. (6 de agosto de 2020). Télam. Recuperada de https://www.telam.com.ar/notas/202008/499164-cordoba-policia-homicidio.html

22. Presidencia de la Nación Argentina. (2013). Los Derechos Humanos Frente a la Violencia Institucional. Recuperado de http://www.bnm.me.gov.ar/giga1/documentos/EL005061.pdf

23. Sangiorgio, B. (23 de marzo de 2020). Indignante: desde un patrullero de la Gendarmería difunden el audio de una película que incita a matar. La Nación. Recuperado de https://www.lanacion.com.ar/seguridad/indignante-patrullero-gendarmeria -difunden-audio-pelicula-incita-nid2346518

24. Santiago, A. y Bellocchio L. (2018). Historia de la Corte Interamericana de Derechos Humanos. Buenos Aires, Argentina: La Ley. 